\title{
The association between ATM variants and risk of breast cancer: a systematic review and meta-analysis
}

\author{
Masoumeh Moslemi ${ }^{1}$, Yousef Moradi ${ }^{2}$, Hojat Dehghanbanadaki ${ }^{3}$, Hamed Afkhami ${ }^{4}$, Mansoor Khaledi ${ }^{4}$, \\ Najmeh Sedighimehr ${ }^{5}$, Javad Fathi ${ }^{6}$ and Ehsan Sohrabi ${ }^{1^{*}}$
}

\begin{abstract}
Background: Ataxia telangiectasia-mutated (ATM) gene contributes to repair damaged DNA and to regulate cell cycle; therefore, ATM variants seem to increase breast cancer risk; however, the results are controversial. So we conducted a systematic review and meta-analysis to clarify the pooled association between various ATM variants and the risk of breast cancer.

Methods: The relevant studies were searched through Scopus, Web of Science, PubMed and Cochrane. Stratified and subgroup analyses were performed to explore heterogeneity between studies and assess effects of study quality. The pooled estimates logarithm with standard error logarithm of odds ratio and relative risk with confidence interval were calculated.

Results: This study revealed that there is association between ATM variants and the risk of breast cancer; according to the seven adjusted case-control studies, OR of this association was estimated as 1.67 (95\%Cl: 0.73-3.82), according to nine unadjusted case-control studies, the crude OR was 2.27 (95\% Cl: 1.17-4.40) and according to two cohorts, the RR was estimated as 1.68 (95\% Cl: 1.17-2.40).

Conclusions: The ATM variants are associated with an increased risk of breast cancer that ATM V2424G mutation is detected as the most predisposing factor while ATM D1853V, L546V, and S707P variants have the least predictive ability.
\end{abstract}

Keywords: Breast cancer, ATM, Variant, Systematic review, Meta-analysis

\section{Background}

Breast Cancer is the most common cancer in women and causes the highest mortality rate in developed and developing countries [1]. Annually, 1.67 million women become infected with this type of cancer and have 522,000 mortality rate each year [2]. According to the World Health Organization (WHO) report, 1 out of 9 women in

\footnotetext{
*Correspondence: h.a.university.ac@gmail.com; e.sohrabi95@gmail.com; sohrabi.e@tak.iums.ac.ir

${ }^{1}$ Department of Medical Genetics and Molecular Biology, Faculty of Medicine, Iran University of Medical Sciences (IUMS), Tehran, Iran Full list of author information is available at the end of the article
}

the world suffers from this type of cancer during their life. The Clinical manifestations of breast cancer are very different in patients and these various manifestations largely depend on the type of genetic mutation. Accurate diagnosis of cancer based on the type of mutation is very helpful for deciding on the treatment and follow up of patients [3].

During the last decade, BRCA1 and BRCA2 mutations (BRCA1/2) have been screened for hereditary breast cancer and results showed that mutations in BRCA1/2 account for $5 \%$ of hereditary breast cancer $[1,4]$. Besides, a recent large population study showed that other

C C The Author(s). 2021 Open Access This article is licensed under a Creative Commons Attribution 4.0 International License, which permits use, sharing, adaptation, distribution and reproduction in any medium or format, as long as you give appropriate credit to the original author(s) and the source, provide a link to the Creative Commons licence, and indicate if changes were made. The images or other third party material in this article are included in the article's Creative Commons licence, unless indicated otherwise in a credit line to the material. If material is not included in the article's Creative Commons licence and your intended use is not permitted by statutory regulation or exceeds the permitted use, you will need to obtain permission directly from the copyright holder. To view a copy of this licence, visit http://creativecommons.org/licenses/by/4.0/. The Creative Commons Public Domain Dedication waiver (http://creativecommons.org/publicdomain/zero/1.0/) applies to the data made available in this article, unless otherwise stated in a credit line to the data. 
pathogenic gene variants, including ataxia telangiectasiamutated (ATM) variants, were frequently detected among breast cancer women $[5,6]$. The ATM gene is located on 11q22-23 chromosome and consists of 66 exons that encode a $350 \mathrm{kDa}$ protein kinase enzyme [7, 8]. This gene plays an important role in regulating the cell cycle and repairing the DNA damage induced by ionizing radiation. Exposure to ionizing radiation, even in very low doses, can trigger a break down significant amount of cellular inactive homodimer ATM to active monomers $[9,10]$. The activated ATM phosphorylates a number of its downstream targets such as p53, chek2 and BRCA1 which stops the cell cycle, repairs DNA or apoptosis, so a mutation in either of these genes causes insufficient cellular repair and ultimately increases the incidence of cancer $[9,11]$.

Mutations in the ATM gene caused Ataxia Telangiectasia (A-T), an autosomal recessive syndrome that patients have symptoms such as ionizing radiation sensitivity, cerebellar neurodegeneration immunodeficiency and markedly increased risk of cancers like breast cancer [12-14]. The incidence of breast cancer among female relatives of A-T families was increased [15-18]. Also, Epidemiologic studies have estimated that obligate heterozygous carriers of an ATM mutation have a 2-5-fold increased risk of breast cancer $[13,19,20]$. In addition, it is reported that breast cancer patients with mutated ATM variants who undergo radiotherapy developed their second tumor sooner than the group with no treatment of radiation and no ATM mutations [21].

Since the detection of the ATM gene in 1995, several studies have been conducted on the association of mutations of this gene and the risk of breast cancer which had contradictory results and to our knowledge, no systematic study was conducted to examine the association between different variants of ATM and breast cancer. Therefore, the current study aims to clarify the pooled relationship between ATM variants and breast cancer.

\section{Main text \\ Methods}

All methods used in this meta-analysis were according to the Preferred Reporting Items for Systematic Reviews and Meta-Analyses statement (PRISMA) [22]. The protocol of this study had been registered in the International Prospective Register of Systematic Reviews (PROSPERO), under the registration number of CRD42018114394.

\section{Search terms and complex search syntax}

To evaluate the relationship between breast cancer and Ataxia Telangiectasia Mutated Proteins, four English databases including Scopus, Web of Science (EMBASE), PubMed, and Cochrane were browsed up to 20 October 2018. In current study "breast carcinoma", "breast tumor", "breast neoplasm", "breast neoplasms", "breast cancer"," breast cancers", "breast tumors", "ataxia telangiectasia mutated", "ataxia telangiectasia mutated proteins", "ATM"," mutation", "mutations", "variant", and "variants" keywords were searched in the mentioned databases. Because of avoiding missing any papers, the reference list of primary articles was screened manually. The primary search results were reviewed, and some articles were eliminated after reviewing their title and abstract. Inclusion and exclusion criteria were set by 2 researchers separately (YM, MM).

\section{Eligibility criteria}

Articles were selected using the following criteria: (1) assessment of the association between ATM variants and breast cancer risk; (2) studies with full text articles; (3) case-control and cohort studies; (4) sufficient data for estimating an odds ratio (OR) with $95 \%$ confidence interval $(\mathrm{CI})$.

\section{Screening and data extraction}

Full texts of each article were sensibly assessed by two independent reviewers (ES and MM) and any probable disagreements with these reviewers were resolved by consultation with another author (YM) to settle the argument, and a concluding deduction was applied. The following data were collected from each study: first author's name, publication date, type of study, country, study population, age, sample size, type of variant, measurement of association and controlled variables.

\section{Quality assessment and risk of Bias}

The qualities of all studies were assessed by Modified Newcastle-Ottawa Scale for Case Control studies [23]. This checklist was completed by two researchers (ES and $\mathrm{MM})$. The quality of studies was judged based on such aspects as selection, comparability and outcome. Scores ranged from 0 stars (worst case) to 9 stars (best case). Studies with a score of 0-4 were categorized as low quality, 5-7 as moderate, and more than 7 as high qualities.

\section{Statistical analysis}

Association between the ATM and breast cancer risk was analyzed by pooling odds ratio (ORs) and risk ratio (RR) with 95\% confidence interval (CIs) using STATA metan module. DerSimonian and Laird method were used to compute the pooled estimate of odds ratio (OR) and risk ratio (RR) with a confidence interval (CI 95\%) using random models [24]. Because the test for heterogeneity was statistically significant in some analyses, the random effects models were used to estimate OR and RR. In the fixed effects model approach, we used two popular methods, which included the inverse varianceweighted average method and the weighted sum of the zscores method. Although previous studies have shown 
that the two methods perform similarly, their characteristics and their relationship have not been thoroughly investigated. Therefore, in present meta-analysis we used the inverse variance-weighted model $[25,26]$. In this study, w Cochran's Q test and I square statistic was used to evaluate statistical heterogeneity between studies [27]. In addition, a meta-regression and subgroup analysis were performed to assess the source of heterogeneity between studies. Moreover, publication bias was assessed by funnel plot and Egger test [28, 29]. Statistical analysis was performed using STATA 14.0 (Stata Corp, College Station, TX, USA) and statistical significance was set at $p<0.05$.

\section{Results}

\section{Study characteristics}

The first step of search in electronic databases yielded 397 publications. In the final step, after removing the duplicates, reviewing by title, abstract and full text and considering the inclusion and exclusion criteria, 18 studies were selected for the meta-analysis of the pooled association between ATM and the risk of breast cancer (Fig. 1). The characteristics of each study included in the current meta-analysis are reported in Tables 1 and 2.

\section{Association between ATM and breast Cancer in case control studies}

\section{Adjusted case-control studies}

The pooled estimate odds ratio after synthesis results of 7 Adjusted case control studies shows that the association between ATM and risk of breast cancer was 1.67

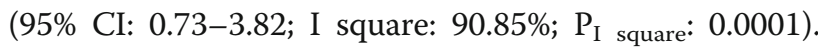
The range of OR between these studies was 0.2 to 11.60 (Fig. 2). The results of Egger's test showed there isn't a publication bias in the association between ATM and

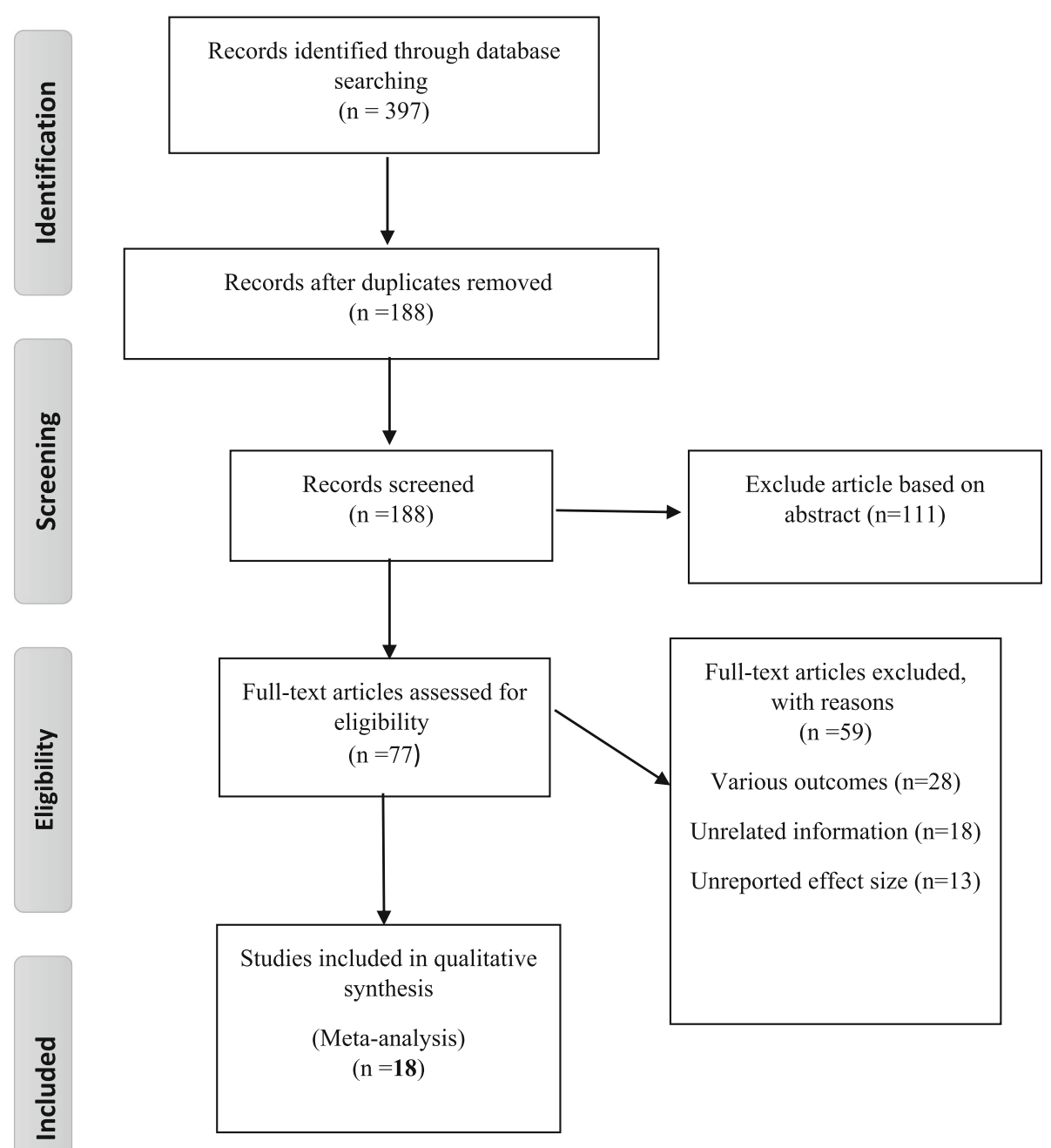

Fig. 1 PRISMA chart outlining the literature search 
Table 1 The main characteristics of cohort and Population based cohort studies of ATM variants on risk of Breast cancer

\begin{tabular}{|c|c|c|c|c|c|c|c|}
\hline $\begin{array}{l}\text { Authors } \\
\text { (years) } \\
\text { (country) } \\
\end{array}$ & Study population & Age & $\begin{array}{l}\text { Sample } \\
\text { size }\end{array}$ & $\begin{array}{l}\text { Type of } \\
\text { variant }\end{array}$ & $\begin{array}{l}\text { Measurement of } \\
\text { association }\end{array}$ & Controlled variables & $\begin{array}{l}\text { NOS } \\
\text { Score }\end{array}$ \\
\hline $\begin{array}{l}\text { Nic Waddell. et al. (15) } \\
\text { (2006) } \\
\text { (South Australia) }\end{array}$ & $\begin{array}{l}\text { South Australia and } \\
\text { Royal Melbourne } \\
\text { Hospita }\end{array}$ & $\begin{array}{l}\text { All } \\
\text { age }\end{array}$ & 782 & $\begin{array}{l}7271 \mathrm{~T}>\mathrm{G} \\
(\mathrm{V} 2424 \mathrm{G})\end{array}$ & $\begin{array}{l}\text { hazard ratio of } 6.1 \\
\text { (95\% Cl: } 1.2-30.8)\end{array}$ & $\begin{array}{l}\text { multiple-case non-BRCA1 and } \\
\text { non- BRCA2 breast cancer } \\
\text { families }\end{array}$ & 7 \\
\hline \multirow{4}{*}{$\begin{array}{l}\text { Sarah Louise } \\
\text { Dombernowsky. } \\
\text { et al. (5) } \\
\text { (2008) } \\
\text { (Denmark) [11] }\end{array}$} & \multirow[t]{4}{*}{$\begin{array}{l}\text { Danish general } \\
\text { population }\end{array}$} & & \multirow[t]{4}{*}{10,324} & Ser49Cys & $\begin{array}{l}\text { Age Adjusted HR } \\
95 \% \mathrm{Cl} \\
1.0(0.5-2.2)\end{array}$ & \multirow{4}{*}{$\begin{array}{l}\text { Heterozygotes versus } \\
\text { Alcohol consumption Smoking } \\
\text { habits } \\
\text { Reproductive history }\end{array}$} & \multirow[t]{4}{*}{7} \\
\hline & & & & & $\begin{array}{l}\text { Multifactorial } \\
\text { Adjusted HR 95\% Cl } \\
0.8(0.3-2.0)\end{array}$ & & \\
\hline & & & & Ser707Pro & $\begin{array}{l}\text { Age Adjusted HR } \\
95 \% \mathrm{Cl} \\
0.60(0.2-1.5)\end{array}$ & & \\
\hline & & & & & $\begin{array}{l}\text { Multifactorial } \\
\text { Adjusted HR 95\% Cl } \\
0.6(0.2-1.6)\end{array}$ & & \\
\hline
\end{tabular}

risk of breast cancer (Coefficient $=2.08 ; P=0.193 ; \% 95$ CI: $-0.56-3.16)$.

The results of subgroup analysis show that the highest association between ATM variants and the risk of breast cancer belongs to the Asian population with an odds ratio of 4.21 (95\%CI: 0.78-22.88; I square: $89.5 \%$; $\mathrm{P}_{\text {I square: }}$ 0.0001 ) while the lowest odds ratio was among the European population that was equal to 1.24 (95\% CI: 0.941.64; I square: $18.5 \%$; $P_{I}$ square: 0.297 ). This suggests that ATM variants have a greater impact on the risk of breast cancer in the Asian population than in the European and American populations (Table 3).

The results based on homo/heterozygosity status of variants show that heterozygous variants had increased the risk of breast cancer with a factor of 1.98 (95\% CI

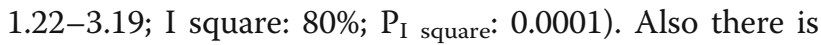
an association between homozygous variants and the risk of breast cancer with an odds ratio (OR) of 1.63 (95\% CI: 1.20-2.22; I square: 0.00\%; $\mathrm{P}_{\mathrm{I}}$ square: 0.929). Meanwhile, the lowest OR belonged to homo or heterozygous which was equal to 1.22 (95\% CI: 1.01-1.46; I square: $0.00 \%$; $\mathrm{P}_{\mathrm{I}}$ square: 0.433$)$. This statistical analysis indicates that heterozygous ATM variants are the most associated with breast cancer incidence (Table 3).

In addition, results of subgroup analysis based on type of variants show that the V2424G variant (c.7271 T > G) is the most associated with breast cancer incidence (OR: 8.94; \%95 CI: 4.28-18.67; I square $=0.00 \%$; $\mathrm{P}_{\mathrm{I}}$ square $=$ 0.789 ) and D1853V has the least impact on breast cancer incidence (OR: 0.43; 95\% CI: 0.09-2.07; 0.031; I square:

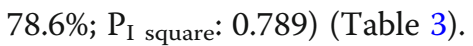

\section{Unadjusted case-control studies}

From the 9 unadjusted case control studies, the association between ATM variants and the breast cancer risk ranged between 0.37 and 12.70 . The pooled estimate of crude odds ratio between ATM and risk of breast cancer was 2.27 (95\% CI: 1.17-4.40; I square: $74.56 \%$; $\mathrm{P}_{\mathrm{I} \text { square: }}$ 0.0001) (Fig. 3). The results of Egger's test showed no publication bias in the association between ATM and risk of breast cancer in unadjusted case control studies (Coefficient: 0.398; P: 0.193; \% 95 CI: - 0.21 - 1.00).

Subgroup analysis based on continent shows that ATM variants have a greater impact on breast cancer incidence in the Asian population than in the European and American populations (Table 3). In addition, the heterozygote ATM variants increased the risk of breast cancer 1.31 times (95\% CI: 1.05-1.64; I Square: 83.0\%; $\mathrm{P}_{\mathrm{I}}$ square: 0.0001) (Table 3 ).

Also, the evaluation of the effect of different variants of ATM Gene on the incidence of breast cancer shows that c.7271 T > G has the highest association with an OR of 27.97 (95\% CI: 5.01-35.07; I Square: 62.0\%; $\mathrm{P}_{\mathrm{I} \text { square: }}$ 0.105 ) and L546V has the lowest association with an OR of 0.37 (95\% CI 0.19-0.73; 0.032; I Square:58.9; $\mathrm{P}_{\text {I square: }}$ 0.105) (Table 3).

\section{Association between ATM and breast Cancer in cohort studies \\ Cohort studies}

The results of two cohort studies showed a risk ratio (RR) range of 0.6 to 6.10 . The pooled risk ratio between ATM variants and risk of breast cancer was 1.68 (95\% CI: 1.17-2.40; 0.032; I square: $62.1 \%$; $P_{\text {I square: }} 0.105$ ).

\section{Discussion}

ATM gene has been recognized in recent years as a low penetrance breast cancer gene, which is a research goal for many studies [31]. Based on the mentioned keywords 18 articles were evaluated and different variants of this gene in three continents of Asia, America and Africa were analyzed. Qualitative assessment of articles was 


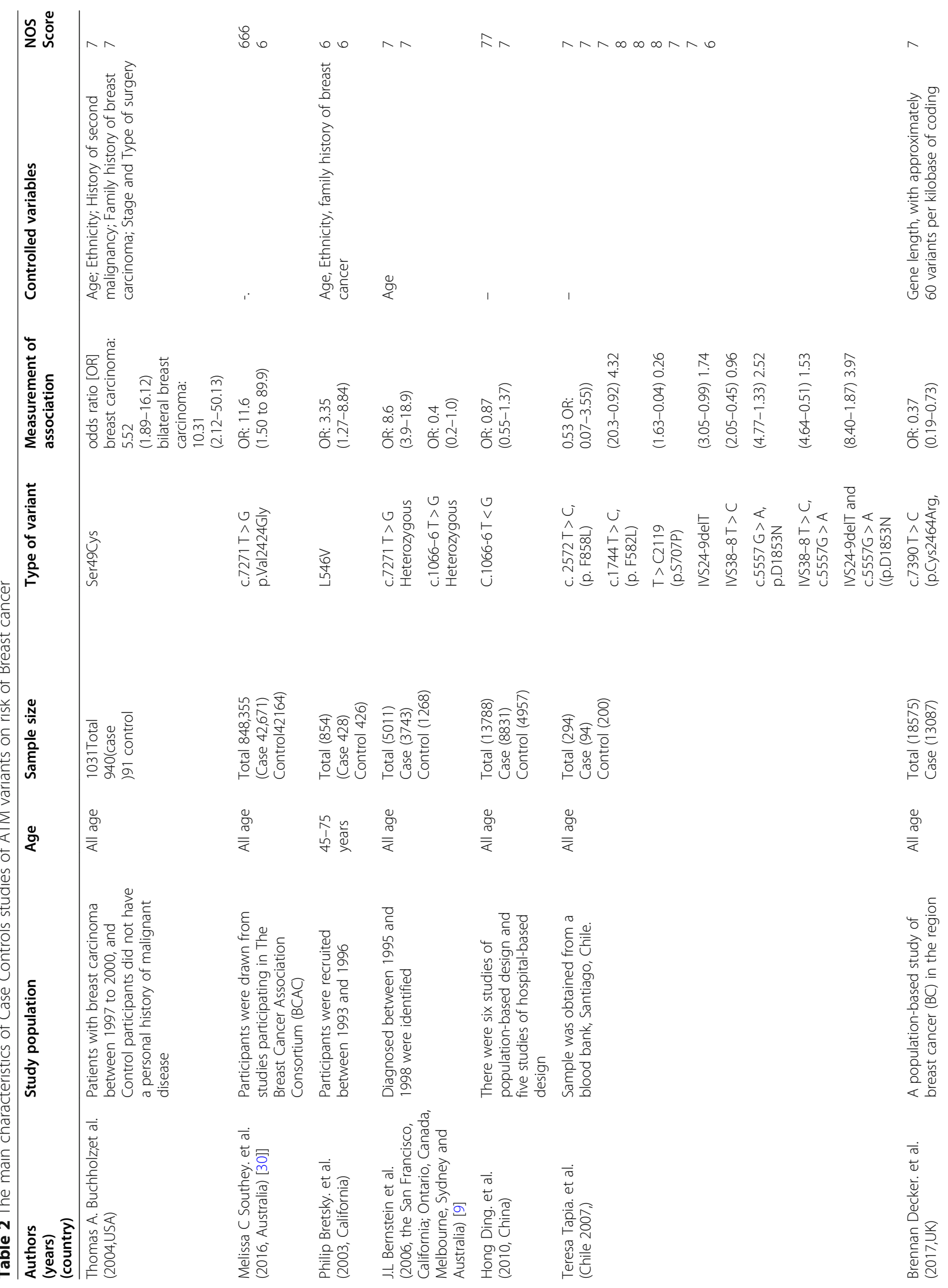


Moslemi et al. BMC Cancer $\quad$ (2021) 21:27

Page 6 of 12

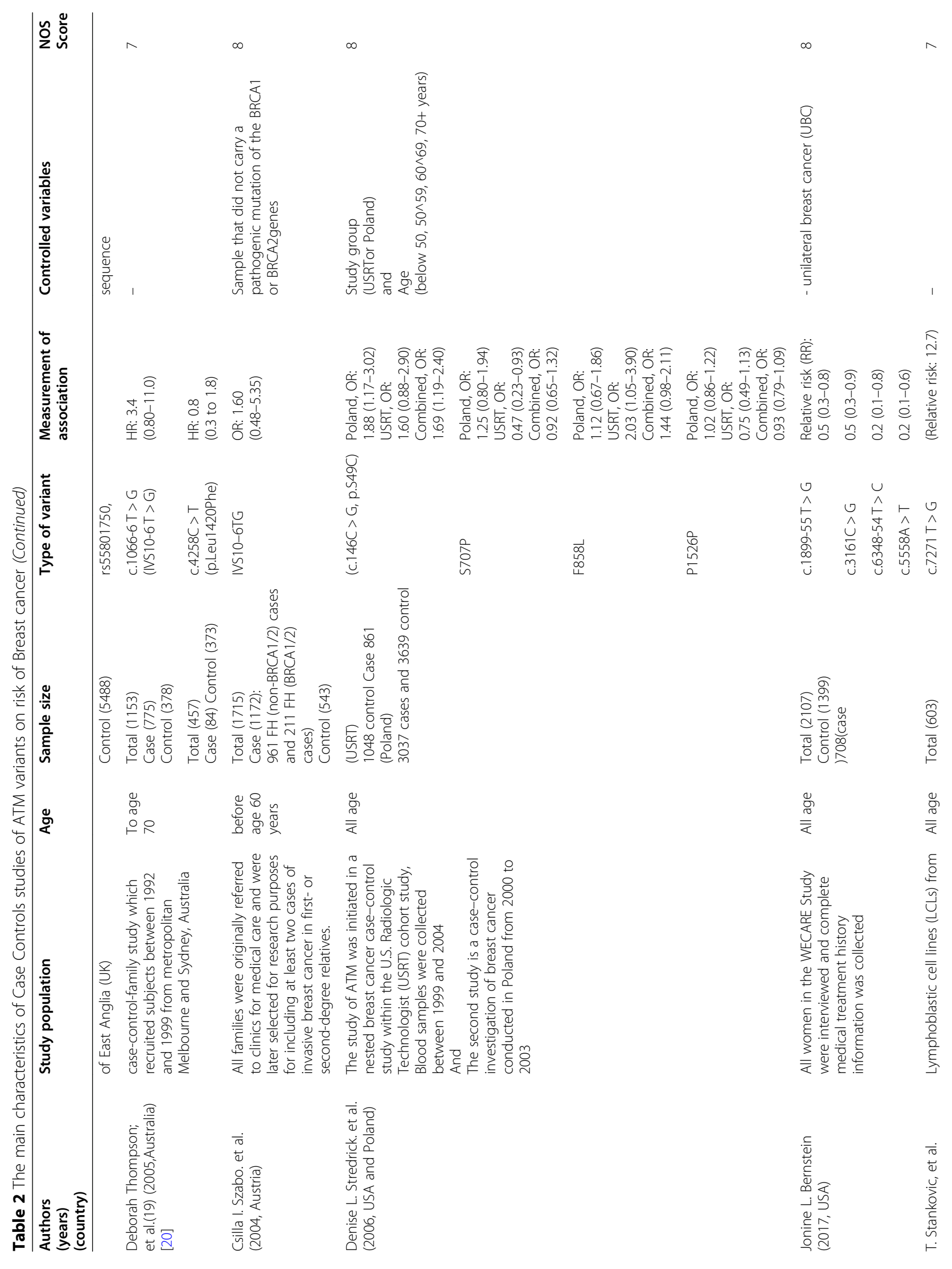




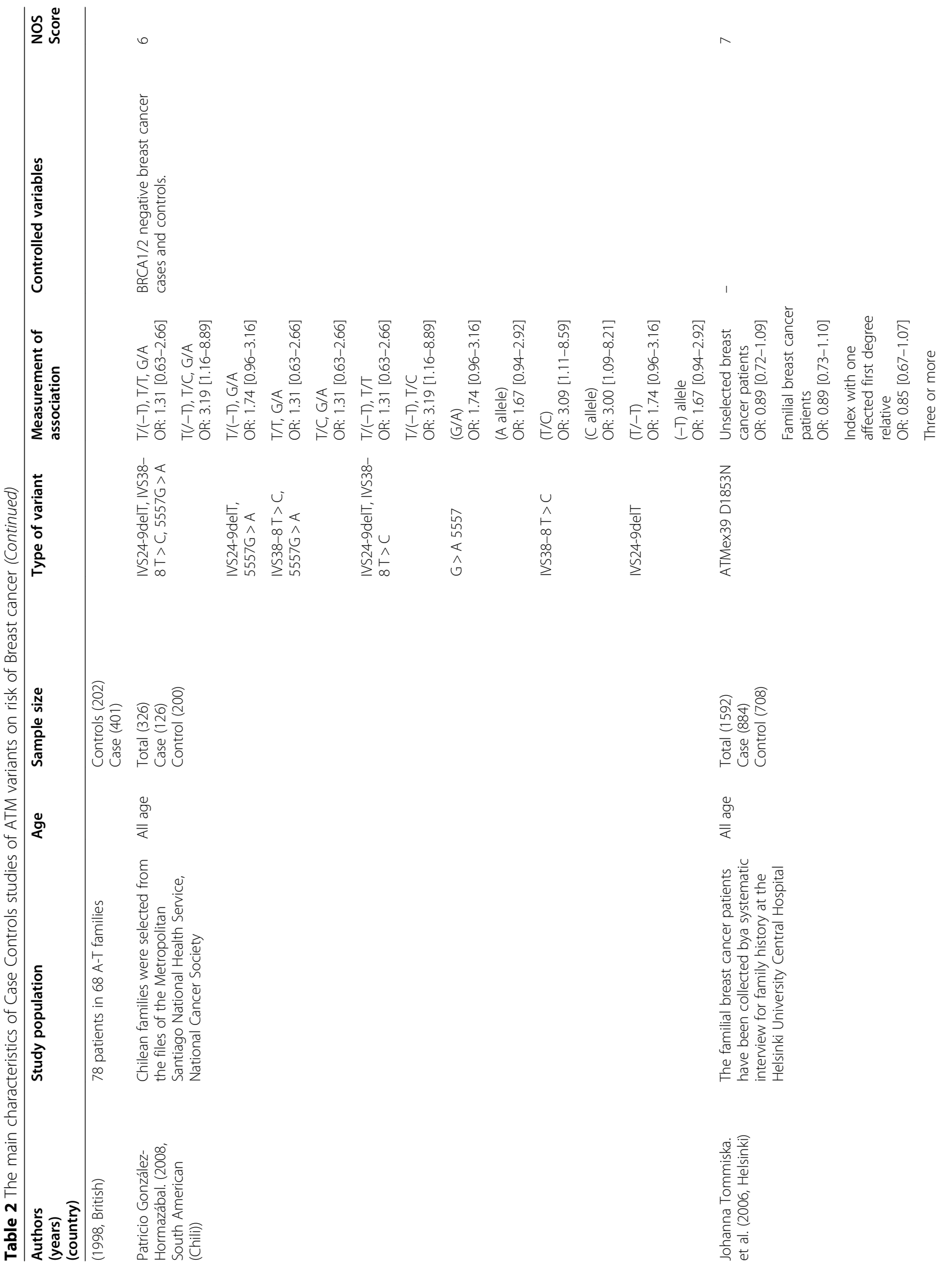




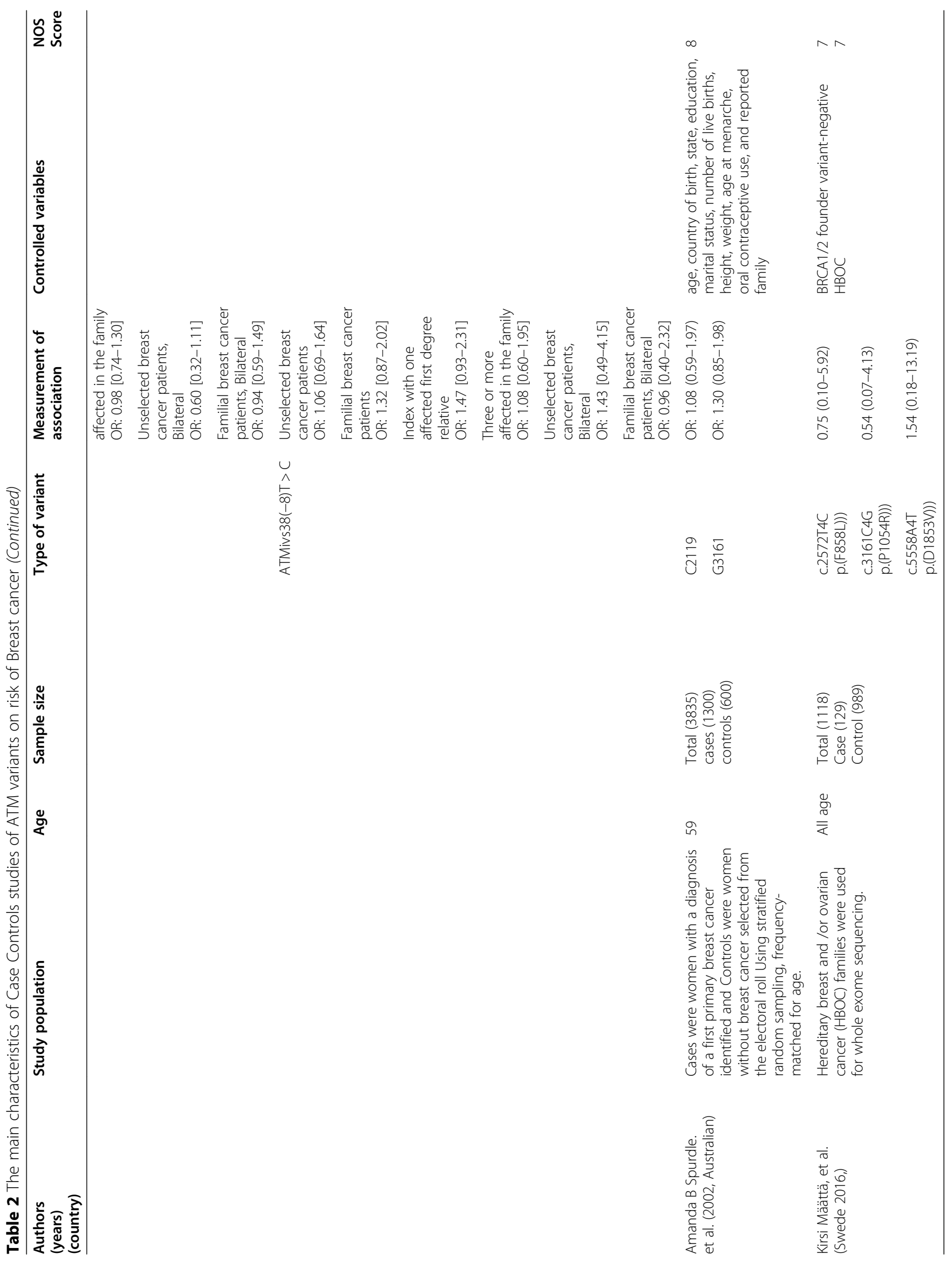




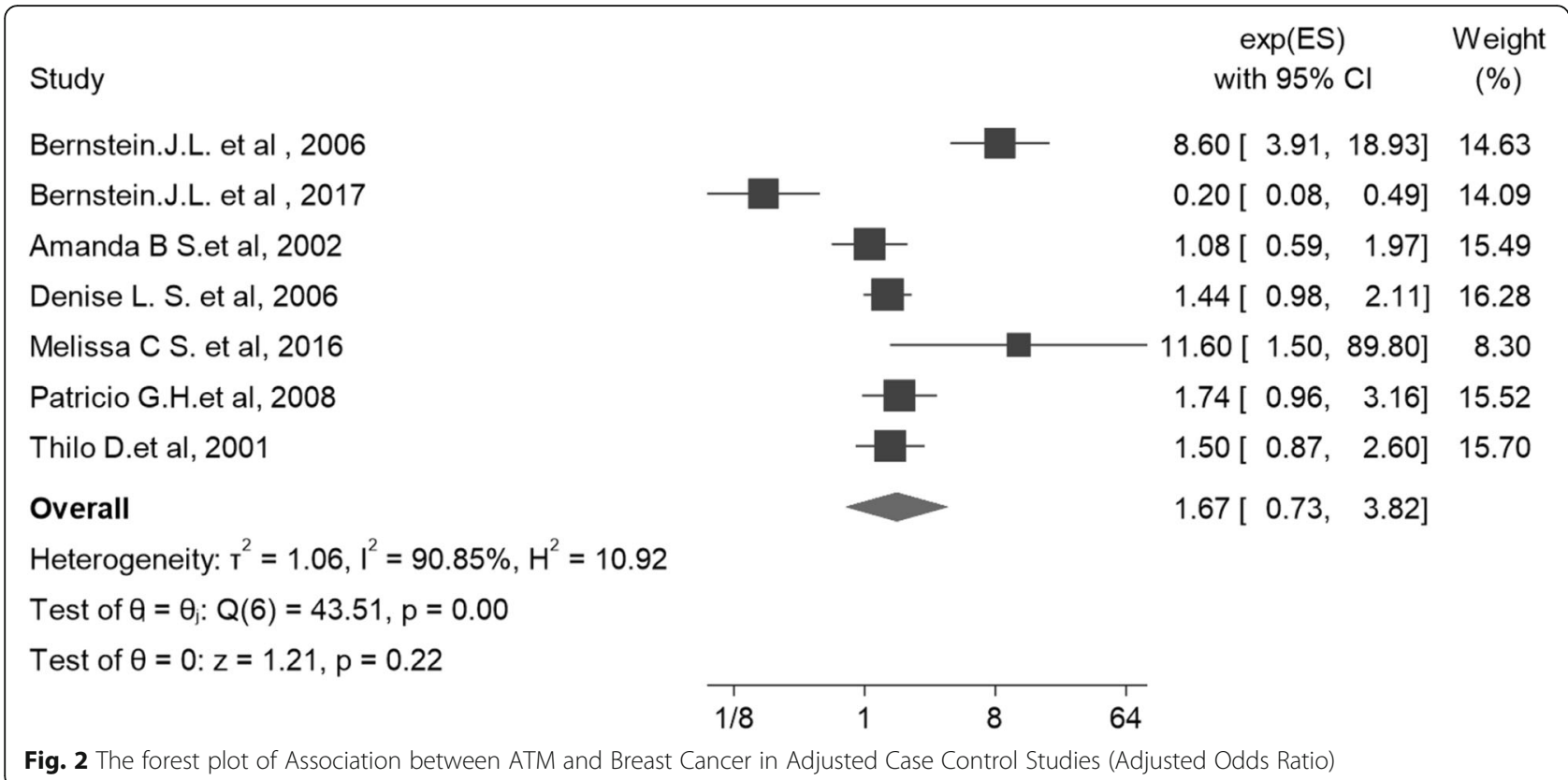

performed by NOS criteria and the results showed that all articles are of medium to high quality, so they met the criteria for entering meta-analysis. The results of the current study indicate that ATM missense variants increase the incidence of breast cancer and people who carry these variants have an increased risk of developing breast cancer.

In the study by Easton DF et al. [32] in 2015, it is reported that relatives of A-T patients encounter breast cancer with a relative risk of $2.8(90 \% \mathrm{CI}: 2.2-3.7 ; P<$ 0.0001 ) [32]. Another study by van $\mathrm{Os} \mathrm{NJH}$ et al. [33] in 2016 demonstrated that all women with pathogenic ATM variants developed breast cancer with a relative risk of 3.04 (90\%CI: $2.06-4.48 ; P<0.0001)$. Another meta-analysis of 19 studies by Marabelli $M$ et al. [34] in 2016 reported that the women who were the carriers of ATM variants have a breast cancer relative risk of 6.02 (90\%CI: $4.58-7.42$ ) by the age of 50 years old and 32.83 (90\%CI: $24.55-40.43$ ) by the age of 80 years old [34]. As the same as our findings, all these studies emphasized that there is a strong association between ATM variants and the risk of breast cancer development.

Of the 29 different variants examined in the current study, V2424G (c.7271 T > G) missense variant had the highest association with breast cancer incidence in different subgroups of adjusted case control, non-adjusted case control and cohort studies. Although this association varied across the three subgroups analyses, all revealed that V2424G missense variant was strongly accompanied by an increased risk of breast cancer. Bernstein JL et al. [9] in 2006 reported that women who were carriers with V2424G missense variant had developed breast cancer by the age of 70 years old with a cumulative risk of $52 \%(95 \% \mathrm{CI}=28-80 \% ; P<0.0001)$. Another study by Goldgar DE et al. [35] in 2011 analyzed 15 different A-T families and revealed that pathogenic V2424G variant accompanied with increased risk of breast cancer with a relative risk of 8 (95\% CI: 2.3-27.4; $P=0.0005$. In addition, another study by Southey MC et al. [30] in 2016 reported that V2424G missense variant was detected in 12 of 42,671 patients suffered from invasive breast cancer and one of 42,164 normal control population that these statistics results in an OR of 11.0 (95\% CI:1.42-85.7; $p=0.0012$ ). Also, Mitui $\mathrm{M}$ et al. [36] evaluated the clinical consequences of ATM gene alterations using stable transfection and among the 12 missense variants examined, ATM V2424G variant was one of the variants which were associated with an increased risk of cancer.

The meta-analysis on the adjusted case-control studies revealed that ATM D1853V missense variant has the least association with an increased risk of breast cancer. Gao LB et al. [37] in 2010 revealed that there is significantly no relationship between the D1853V missense variant and the risk of breast cancer development [37] that this finding is congruent with our results.

Another objective of our study was to investigate the association of ATM variants with breast cancer in different regions. Although the incidence of breast cancer is higher in the Americas and Europe than in the Asian continent $[38,39]$, it is interesting to note that the association between ATM variants and breast cancer is 
Table 3 Summary odds ratio (OR) or relative risk (RR) Estimates [95\% confidence intervals (Cls)] for observational studies conducted on The association between ATM variants and risk of breast cancer

\begin{tabular}{|c|c|c|c|c|c|c|c|}
\hline \multirow[t]{2}{*}{ Subgroup } & \multirow{2}{*}{$\begin{array}{l}\text { Number } \\
\text { OR in } \\
\text { primary } \\
\text { studies }\end{array}$} & \multirow{2}{*}{$\begin{array}{l}\text { Summery effect } \\
\text { size }(95 \% \mathrm{Cl})\end{array}$} & \multicolumn{3}{|c|}{ Between studies } & \multicolumn{2}{|c|}{ Between subgroups } \\
\hline & & & $\overline{1^{2}}$ & $P_{\text {heterogeneity }}$ & $z$ & $\bar{Q}$ & $P_{\text {heterogeneity }}$ \\
\hline \multicolumn{8}{|l|}{ Adjusted Case Control studies } \\
\hline \multicolumn{8}{|l|}{ Heterozygosity variants } \\
\hline Hetro & 13 & $1.98(1.22-3.19)$ & $80 \%$ & 0.0001 & 2.78 & 5.03 & 0.0001 \\
\hline Hemo & 4 & $1.63(1.20-2.22)$ & $0.0 \%$ & 0.929 & 2.12 & & \\
\hline Hetro/Hemo & 7 & $1.22(1.01-1.46)$ & $0.0 \%$ & 0.433 & 3.14 & & \\
\hline \multicolumn{8}{|l|}{ Continent } \\
\hline Asia & 2 & $4.21(0.78-22.88)$ & $89.5 \%$ & 0.0001 & 1.67 & 4.03 & 0.0001 \\
\hline America & 3 & $1.55(1.19-2.01)$ & $60.4 \%$ & 0.001 & 3.22 & & \\
\hline European & 2 & $1.24(0.94-1.64)$ & $18.5 \%$ & 0.297 & 1.49 & & \\
\hline \multicolumn{8}{|l|}{ Type } \\
\hline c.7271 T > G & 2 & $8.94(4.28-18.67)$ & $0.0 \%$ & 0.789 & 5.83 & & \\
\hline D1853V & 2 & $0.43(0.09-2.07)$ & $78.6 \%$ & 0.031 & 1.05 & & \\
\hline S707P & 3 & $1.17(0.73-1.87)$ & $49.2 \%$ & 0.140 & 0.66 & 4.03 & 0.0001 \\
\hline F858L & 2 & $1.43(1.02-2.00)$ & $0.0 \%$ & 0.943 & 2.10 & & \\
\hline IVS38-8T > C, c.5557G > A & 2 & $1.90(0.80-4.48)$ & $48.9 \%$ & 0.162 & 1.46 & & \\
\hline IVS38-8T >C & 2 & $3.04(1.48-6.25)$ & $0.0 \%$ & 0.963 & 3.04 & & \\
\hline IVS24-9delT & 2 & $1.70(1.13-2.57)$ & $0.0 \%$ & 0.922 & 2.54 & & \\
\hline $5557 G>A$ & 3 & $1.33(0.89-1.99)$ & $54.7 \%$ & 0.110 & 1.39 & & \\
\hline IVS24-9delT, IVS38-8 T > C, & 2 & $1.90(0.80-4.48)$ & $48.9 \%$ & 0.162 & 1.46 & & \\
\hline $5557 G>A$ & 2 & $1.90(0.80-4.48)$ & $48.9 \%$ & 0.162 & 1.46 & & \\
\hline \multicolumn{8}{|l|}{ IVS24-9delT, IVS38-8 T > C } \\
\hline \multicolumn{8}{|l|}{ Unadjusted Case Control studies } \\
\hline \multicolumn{8}{|l|}{ Heterozygosity variants } \\
\hline Hetro & 28 & $1.31(1.05-1.64)$ & $76.3 \%$ & 0.0001 & 2.35 & 3.89 & 0.001 \\
\hline Hetro/Hemo & 3 & $3.43(0.99-11.84)$ & $90.9 \%$ & 0.0001 & 1.95 & & \\
\hline \multicolumn{8}{|l|}{ Continent } \\
\hline Asia & 3 & $5.37(1.66-17.48)$ & $86.5 \%$ & 0.0001 & 2.79 & & \\
\hline America & 2 & $1.58(1.07-2.33)$ & $67.8 \%$ & 0.0001 & 2.32 & 3.89 & 0.0001 \\
\hline European & 4 & $1.08(0.85-1.38)$ & $74.8 \%$ & 0.0001 & 0.63 & & \\
\hline \multicolumn{8}{|l|}{ Type } \\
\hline c.1066-6T > G & 8 & $1.69(0.91-3.14)$ & $78.1 \%$ & 0.0001 & 1.67 & & \\
\hline Ser49Cys & 3 & $9.24(4.78-17.87)$ & $0.0 \%$ & 0.468 & 6.61 & & \\
\hline $7271 \mathrm{~T}>\mathrm{G}(\mathrm{V} 2424 \mathrm{G})$ & 2 & $27.97(5.01-35.07)$ & $62 \%$ & 0.105 & 3.80 & 3.89 & 0.0001 \\
\hline IVS38-8T >C & 6 & $1.22(0.98-1.51)$ & $0.0 \%$ & 0.874 & 1.78 & & \\
\hline D1853N & 6 & $1.22(0.98-1.51)$ & $58.9 \%$ & 0.032 & 0.67 & & \\
\hline
\end{tabular}

greater in Asian countries than in American and European countries in all three sub-groups analyses that is probably due to racial differences, environmental conditions, patterns of life and the effects of other genes or specific haplotype combinations in that region [39].

The overall risk heterogeneity in our study was 67.4 , which could be due to the way we measured, sample-sizes designs, inclusion criteria, family history and BRCA1/2 mutation status and could distort the interpretation of our results, so we performed a sub-group analysis based on variant type, region and heterozygosity to illustrate this heterogeneous factor and thus reduced the heterogeneity up to zero. 


\begin{tabular}{|c|c|c|c|}
\hline Study & & $\begin{array}{c}\exp (\mathrm{ES}) \\
\text { with } 95 \% \mathrm{Cl}\end{array}$ & $\begin{array}{c}\text { Weight } \\
(\%)\end{array}$ \\
\hline Määttäl K. et al, 2016 & - & $1.54[0.18,13.18]$ & 6.00 \\
\hline Brennan D. et al, 2017 & - & $0.37[0.19,0.73]$ & 13.78 \\
\hline Csilla I. S. et al, 2004 & & $1.60[0.48,5.34]$ & 10.50 \\
\hline Deborah T. et al, 2005 & & $3.40[0.92,12.61]$ & 9.88 \\
\hline Hong D. et al, 2010 & & $1.86[0.96,3.61]$ & 13.84 \\
\hline Stankovic.T. et al, 1998 & - & $12.70[3.52,45.80]$ & 10.04 \\
\hline Teresa T. et al, 2006 & 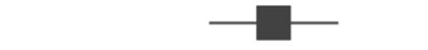 & $3.97[1.87,8.42]$ & 13.31 \\
\hline Thomas A. B. et al, 2004 & - & $5.52[1.89,16.12]$ & 11.32 \\
\hline Tommiska J. et al, 2006 & 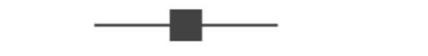 & $1.43[0.49,4.16]$ & 11.34 \\
\hline Overall & & $2.27[1.17,4.40]$ & \\
\hline Heterogeneity: $\mathrm{T}^{2}=0.72, \mathrm{I}^{2}=74.56 \%, \mathrm{H}^{2}=3.93$ & & & \\
\hline Test of $\theta=\theta_{\mathrm{j}}: \mathrm{Q}(8)=39.73, p=0.00$ & & & \\
\hline Test of $\theta=0: z=2.41, p=0.02$ & & & \\
\hline & $1 / 4$ & & \\
\hline
\end{tabular}

\section{Limitation}

Since the primary studies used in this meta-analysis did not provide sufficient information about the exact age of the patients, the type of breast cancer, its stage and grade, the hereditary or sporadic type and unilateral or bilateral breast cancer, further subgroup analysis was not possible. Furthermore, there are few cohort studies in this area, and we need more studies.

\section{Conclusion}

This meta-analysis shows that the pathogenic ATM variants are associated with an increased risk of breast cancer. Accordingly, ATM variants, including V2424G have the highest risk of breast cancer incidence while ATM D1853V, L546V, and S707P variants have the least impact on breast cancer incidence.

\section{Abbreviations}

Cl: Confidence Interval; RR: Risk Ratio or Relative Risk; OR: Odds Ratio; BMI: Body Weight Index; CINAHL: Cumulative Index to Nursing and Allied Health Literature; EMBASE: Excerpta Medica dataBASE; PRISMA: Preferred Reporting Items for Systematic Reviews and Meta-Analyses statement; NOS: Modified Newcastle-Ottawa Scale; ATM: Ataxia telangiectasia-mutated; STROBE: Strengthening the Reporting of Observationally Studies in Epidemiology; PROSPERO: International Prospective Register of Systematic Reviews

\section{Acknowledgements}

Not applicable.

\section{Authors' contributions}

YM, MM and ES conceptualized the idea for this review. YM formulated the review question and objectives and development of the search strategy.
MM, ES, JF and NS carried out the primary search and data extraction. YM contributed to the data analysis/ interpretation. MM, MK, YM, JF and NS write the manuscript draft. MK, HD, HA contributed to the review and final edition. All authors read and approved the final manuscript.

\section{Funding}

Not applicable.

Availability of data and materials

All data generated or analyzed during this study are included in this published article.

Ethics approval and consent to participate

Not applicable.

\section{Consent for publication}

There is no limit to the publication.

\section{Competing interests}

We declare that we have no conflict of interest.

\section{Author details}

'Department of Medical Genetics and Molecular Biology, Faculty of Medicine, Iran University of Medical Sciences (IUMS), Tehran, Iran.

${ }^{2}$ Department of Epidemiology, School of Public Health, Iran University of Medical Sciences, Tehran, Iran. ${ }^{3}$ Students Scientific Research Center, Tehran University of Medical Sciences, Tehran, Iran. ${ }^{4}$ Department of Microbiology, Faculty of Medicine, Shahed University, Tehran, Iran. ${ }^{5}$ Department of Physiotherapy School of Rehabilitation, Shiraz University of Medical Sciences, Shiraz, Iran. ${ }^{6}$ Department of Bacteriology and Virology, School of Medicine, Shiraz University of Medical Sciences, Shiraz, Iran.

Received: 28 July 2020 Accepted: 17 December 2020 Published online: 05 January 2021

\section{References}

1. Moslemi, M., et al., Expression analysis of EEPD1 and MUS81 genes in breast Cancer. 2020. 
2. Määttä $\mathrm{K}$, et al. Whole-exome sequencing of Finnish hereditary breast cancer families. Eur J Hum Genet. 2017;25(1):85.

3. Thorstenson YR, et al. Contributions of ATM mutations to familial breast and ovarian cancer. Cancer Res. 2003;63(12):3325-33.

4. Hirsch AE, Atencio DP, Rosenstein BS. Screening for ATM sequence alterations in African-American women diagnosed with breast cancer. Breast Cancer Res Treat. 2008;107(1):139-44.

5. Desmond $\mathrm{A}$, et al. Clinical actionability of multigene panel testing for hereditary breast and ovarian cancer risk assessment. JAMA Oncol. 2015; 1(7):943-51.

6. Buys SS, et al. A study of over 35,000 women with breast cancer tested with a 25-gene panel of hereditary cancer genes. Cancer. 2017;123(10):1721-30

7. Dörk T, et al. Spectrum of ATM gene mutations in a hospital-based series of unselected breast cancer patients. Cancer Res. 2001;61(20):7608-15.

8. Savitsky $\mathrm{K}$, et al. A single ataxia telangiectasia gene with a product similar to Pl-3 kinase. Science. 1995;268(5218):1749-53.

9. Bernstein J, et al. Population-based estimates of breast cancer risks associated with ATM gene variants c. 7271T> G and c. 1066-6T> G (IVS10-6T> G) from the breast Cancer family registry. Hum Mutat. 2006; 27(11):1122-8

10. Abraham RT. PI 3-kinase related kinases:'big'players in stress-induced signaling pathways. DNA repair. 2004;3(8-9):883-7.

11. Dombernowsky SL, et al. Risk of cancer by ATM missense mutations in the general population. J Clin Oncol. 2008;26(18):3057-62.

12. Bogdanova, N., et al., A nonsense mutation (E1978X) in the gene is associated with breast cancer. 2008.

13. Swift $\mathrm{M}$, et al. Breast and other cancers in families with ataxia-telangiectasia. N Engl J Med. 1987;316(21):1289-94.

14. Chen J, et al. The role of ataxia-telangiectasia heterozygotes in familial breast cancer. Cancer Res. 1998:58(7):1376-9.

15. Milne RL. Variants in the ATM gene and breast cancer susceptibility. Genome Med. 2009:1(1):12.

16. Broeks A, et al. ATM-heterozygous germline mutations contribute to breast cancer-susceptibility. Am J Hum Genet. 2000;66(2):494-500.

17. Athma P, Rappaport R, Swift M. Molecular genotyping shows that ataxiatelangiectasia heterozygotes are predisposed to breast cancer. Cancer Genet Cytogenet. 1996;92(2):130-4.

18. Inskip $\mathrm{H}$, et al. Risk of breast cancer and other cancers in heterozygotes for ataxia-telangiectasia. Br J Cancer. 1999;79(7):1304.

19. Fletcher $\mathrm{O}$, et al. Missense variants in ATM in 26,101 breast cancer cases and 29,842 controls. Cancer Epidemiol Prev Biomarkers. 2010;19(9):2143-51.

20. Thompson D, et al. Cancer risks and mortality in heterozygous ATM mutation carriers. J Natl Cancer Inst. 2005;97(11):813-22.

21. Broeks A, et al. The spectrum of ATM missense variants and their contribution to contralateral breast cancer. Breast Cancer Res Treat. 2008; 107(2):243-8.

22. Hutton B, et al. The PRISMA extension statement for reporting of systematic reviews incorporating network meta-analyses of health care interventions: checklist and explanations. Ann Intern Med. 2015:162(11):777-84.

23. Margulis AV, et al. Quality assessment of observational studies in a drugsafety systematic review, comparison of two tools: the Newcastle-Ottawa scale and the RTI item bank. Clin Epidemiol. 2014;6:359.

24. DerSimonian R, Laird N. Meta-analysis in clinical trials. Control Clin Trials. 1986;7(3):177-88

25. Schmidt FL, Hunter J. General mental ability in the world of work: occupational attainment and job performance. J Pers Soc Psychol. 2004; 86(1):162.

26. Schmidt FL, Oh IS, Hayes TL. Fixed-versus random-effects models in metaanalysis: model properties and an empirical comparison of differences in results. Br J Math Stat Psychol. 2009;62(1):97-128.

27. Higgins J, Thompson SG. Quantifying heterogeneity in a meta-analysis. Stat Med. 2002;21(11):1539-58.

28. Egger M, Smith GD, Minder C. Bias in meta-analysis detected by a simple, graphical test. Br Med J. 1998;316(7129):470-1.

29. Egger $\mathbf{M}$, et al. Bias in meta-analysis detected by a simple, graphical test. Bmj. 1997;315(7109):629-34.

30. Southey MC, et al. PALB2, CHEK2 and ATM rare variants and cancer risk: data from COGS. J Med Genet. 2016;53(12):800-11.

31. Gatti RA, Tward A, Concannon P. Cancer risk in ATM heterozygotes: a model of phenotypic and mechanistic differences between missense and truncating mutations. Mol Genet Metab. 1999;68(4):419-23.
32. Easton $\mathrm{DF}$, et al. Gene-panel sequencing and the prediction of breastcancer risk. N Engl J Med. 2015;372(23):2243-57.

33. van Os $\mathrm{N}$, et al. Health risks for ataxia-telangiectasia mutated heterozygotes: a systematic review, meta-analysis and evidence-based guideline. Clin Genet. 2016;90(2):105-17.

34. Marabelli M, Cheng SC, Parmigiani G. Penetrance of ATM gene mutations in breast cancer: a meta-analysis of different measures of risk. Genet Epidemiol. 2016;40(5):425-31.

35. Goldgar DE, et al. Rare variants in the ATM gene and risk of breast cancer. Breast Cancer Res. 2011;13(4):R73.

36. Mitui $\mathrm{M}$, et al. Functional and computational assessment of missense variants in the ataxia-telangiectasia mutated (ATM) gene: mutations with increased cancer risk. Hum Mutat. 2009;30(1):12-21.

37. Gao L-B, et al. The association between ATM D1853N polymorphism and breast cancer susceptibility: a meta-analysis. J Exp Clin Cancer Res. 2010; 29(1):117

38. Bray F, et al. Global cancer statistics 2018: GLOBOCAN estimates of incidence and mortality worldwide for 36 cancers in 185 countries. CA Cancer J Clin. 2018;68(6):394-424.

39. Porter PL. Global trends in breast cancer incidence and mortality. Salud Publica Mex. 2009;51:s141-6.

\section{Publisher's Note}

Springer Nature remains neutral with regard to jurisdictional claims in published maps and institutional affiliations.
Ready to submit your research? Choose BMC and benefit from:

- fast, convenient online submission

- thorough peer review by experienced researchers in your field

- rapid publication on acceptance

- support for research data, including large and complex data types

- gold Open Access which fosters wider collaboration and increased citations

- maximum visibility for your research: over $100 \mathrm{M}$ website views per year

At $\mathrm{BMC}$, research is always in progress.

Learn more biomedcentral.com/submissions 